\title{
Performance Evaluation of Multiple Transceiver FSO for different Weather Conditions
}

\author{
Priyanka sharma $^{1}$ and Mrs. Himali sarangal ${ }^{2}$ \\ ${ }^{1}$ Student at G.N.D.U \\ ${ }^{2}$ Assistant professor at G.N.D.U \\ ${ }^{1}$ s.priyanka1191@gmail.com, ${ }^{2}$ himali.sarangal@gmail.com
}

\begin{abstract}
Free Space Optical Communication has been developed to cover the longer distances with the growing needs of high speed. It is a data transmission technology from one point to another point by using laser beam carrying information in free space. Multiple transmitters/receivers $(T X / R X)$ are used to improve the performance and quality of Free Space Optics (FSO) communication system under different weather conditions. This paper analyzes the performance of multiple transceivers system by the received power level (PR), $Q$ factor and bit error rate (BER) under clear, fog and haze conditions. From the measured data is possible to calculate visibility which is the main factor for quality and estimation for the availability and reliability of FSO link. The Free Space Optical link was modelled and simulated using a commercial optical system simulator named OptiSystem by Optiwave.
\end{abstract}

Keywords: Free Space Optics (FSO), Spatial Diversity, Q Factor, Bit Error Rate

\section{Introduction}

Free space optical (FSO) (i.e., optical wireless) communication provides an attractive approach to RF-based wireless communication and is a line of sight technology. Distance between transmitting and receiving points can be from several meters up to a few kilometers. It is a growing up technology which offers full duplex and usually protocol independent data transmission between two stations. line of site communication can be possible without the turbulence environment and it is very much efficient in indoor or obstacle less place but in outdoor communication there is environmental effect like fog, haze, rain and dust that limits the FSO link[1]. Signal diverts from its actual path by the scattering caused by different earth unequal points The combination of environmental attenuation and earth inequalities losses provides total attenuation. For better communication we also need large link distance, less scattering, less absorption, less misaiming, large laser power \& data bits. We also have to make a reduced cost, faster implementation and easy installable over long distances[2]. To get these and to reduce the effect of these environmental conditions we need a special quality of FSO link.

\section{Spatial diversity in FSO}

High quality services can be obtained by sending several copies of same signal with the help of diversity. Spatial diversity is a type of diversity based on having multiple antennas at the transmitter and the receiver[3]. Throughput of the channel can be increased linearly with every pair of antenna added to the system. The use of multiple antennas in spatial increases the reliability and availability by simultaneously transmitting the same signal. Spatial diversity is known as transmit diversity if multiple antennas are used for transmission purpose and receive diversity when multiple antennas are used for receiving purposes[4]. In FSO communication system, quality of the signal decreases due to 
environmental effect like fog, haze, rain and dust. In spatial diversity,it is possible to reduce fading and in response quality of signal can be increased. To provide diversity in a system multiple lenses are used in the transmitter and receiver section. Multiple beams from the transmitter are send to different paths using lenses,beams after propagation through the channel get attenuated due to atmospheric disturbances. The attenuation faced by each path will be different and the multiple copies of transmitted signal are then received at the receiver section using lenses[5].

\section{System Design}

The fundamental elements that form the FSO system are the FSO transmitter, channel and receiver. Analysis of performance of Multiple Transreciever system in FSO link is done by using the OptiSystem Version 7.0. The power of the TX is set to be $10 \mathrm{dbm}$ and the frequency is $353 \mathrm{THz}$ or $850 \mathrm{~nm}$. The output of the each TX is connected to the respective fork which is used to replicate the number of output ports so that signals coming out from their respective fork's output has the same value with the output signal from the former component connected to it. From a single source multiple laser beams are produced by the first fork connected to the TX[6]. Then, the output signals will be connected to another set of forks respectively to produce another set of multiple laser beams. Then before sending to the FSO channel these multiple laser beams are combined together with a power combiner. The output coming out from the power combiners are then sent to the FSO channel. This system is a subsystem of two telescopes with the intermediate FSO channel. The apertures of the Transmitter and Receiver are set to $2.5 \mathrm{~cm}$ and $8 \mathrm{~cm}$ respectively. The distance of the channel is set to $2 \mathrm{~km}$ and the beam divergence is $2 \mathrm{mrad}$. The work will involve the modification of the single Transmitter and Receiver layout design to enable the simulation of the multiple Transceivers.

Table 1. Parameters Chosen

\begin{tabular}{|l|l|l|}
\hline PARAMETER & SYM-BOL & VALUE \\
\hline Transmission data rate & Bit rate & $1.25 \mathrm{gbps}$ \\
\hline Link distance & $\mathrm{Z}$ & $2 \mathrm{~km}$ \\
\hline Transmitted power & $\mathrm{Pt}$ & $10 \mathrm{dbm}$ \\
\hline Wavelength & $\mathrm{F}$ & $850 \mathrm{~nm}$ \\
\hline Transmitter aperture & $\mathrm{Dt}$ & $2.5 \mathrm{~cm}$ \\
\hline Receiver aperture & $\mathrm{Dr}$ & $8 \mathrm{~cm}$ \\
\hline Extinction ratio & Re & $10 \mathrm{db}$ \\
\hline Beam divergence & theta & $2 \mathrm{mrad}$ \\
\hline Equipment loss & Leqip & $3.6 \mathrm{db}$ \\
\hline Line width & W & $10 \mathrm{Mhz}$ \\
\hline
\end{tabular}

In practical cases there is attenuation in the received signal due to weather conditions of the channel. We should set the attenuation losses in the FSO. Typical attenuation values of three conditions clear, fog and haze are $0.43 \mathrm{~dB} / \mathrm{km}, 43 \mathrm{~dB} / \mathrm{km}$ and $4.3 \mathrm{~dB} / \mathrm{km}$ respectively [7]. At first the attenuation value is set as $0.43 \mathrm{~dB} / \mathrm{km}$ (clear). The optical signal is received by optical receiver in the FSO channel. These simulations include three visualizer's namely optical power meter, BER analyser and optical spectrum analyser. Optical spectrum analyzers analyse the optical spectrum. Optical power meters can measure the power received in both $\mathrm{dBm}$ and Watts. BER analyzer can calculate the BER value, display eye diagram and $\mathrm{Q}$ factor. 


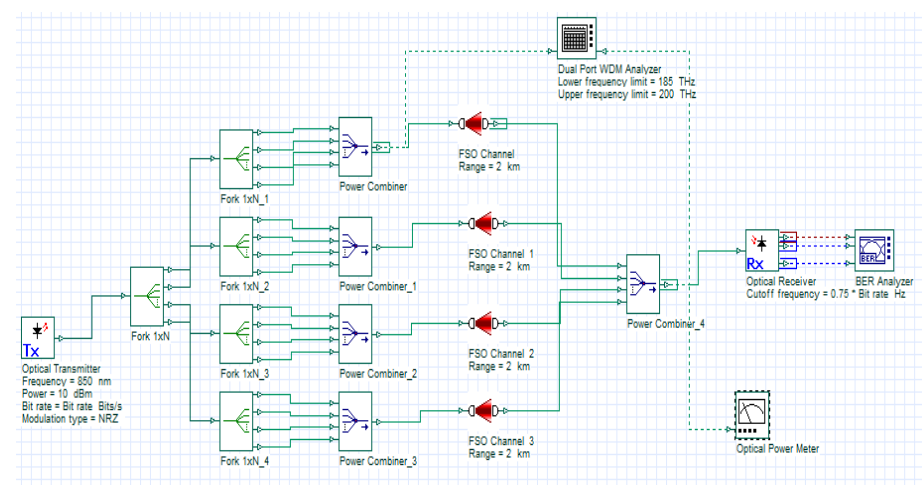

Figure 1. Simulation Layout of 4Tx/4Rx FSO System



Figure 2. Simulation Layout of 8Tx/8Rx FSO System

\section{Results and Discussions}

Simulations of both $1 \mathrm{TX} / 1 \mathrm{RX}, 4 \mathrm{TX} / 4 \mathrm{RX}$ amd $8 \mathrm{TX} / 8 \mathrm{RX}$ FSO systems with a power of $10 \mathrm{dBm}$, range of $2 \mathrm{~km}$ and bit rate of $1.25 \mathrm{Gbps}$ are analysed under three conditions clear, haze and fog. Figure 3 represents the FSO system under clear condition. 4 TX/4 RX show a better performance with high $Q$ factor and low BER. 


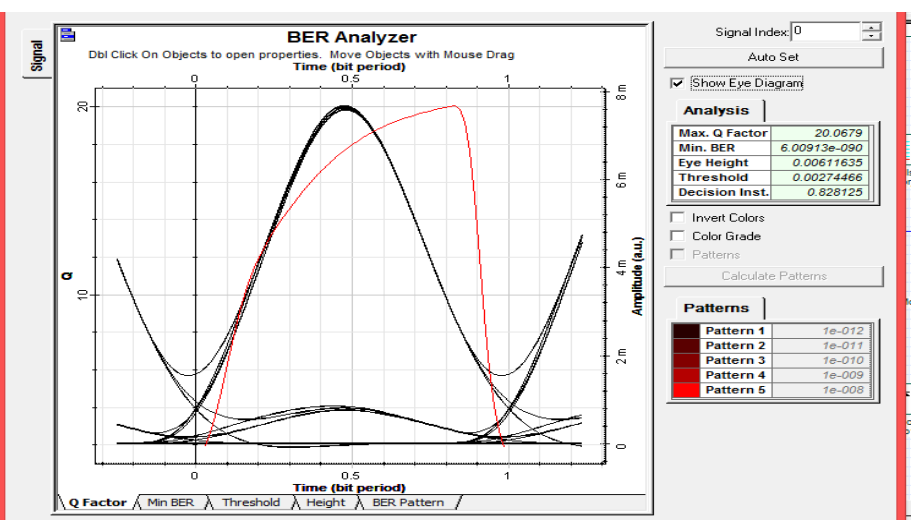

Figure 3.1. Eye Diagram of Single Tx/Rx during Normal Conditions



Figure 3.2. Eye Diagram of $4 \mathrm{Tx} / 4 \mathrm{Rx}$ during Normal Conditions

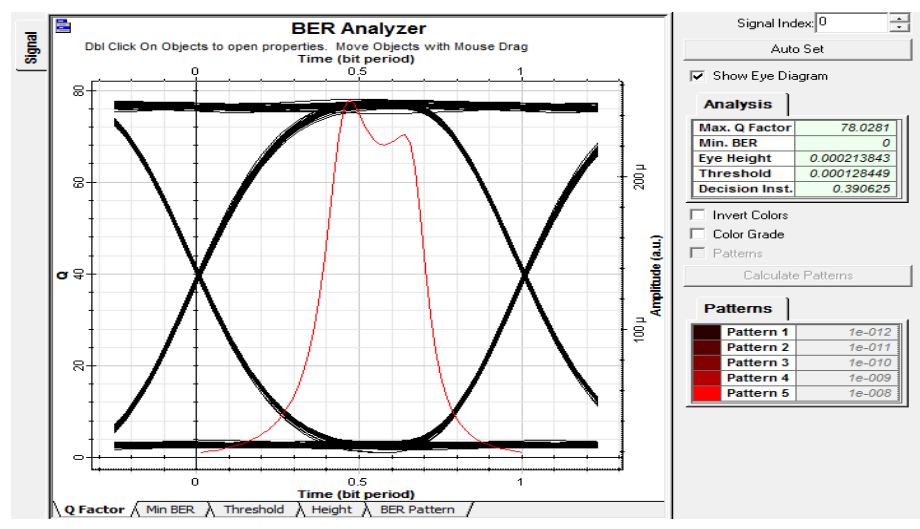

Figure 3.3. Eye Diagram of $8 \mathrm{Tx} / 8 \mathrm{Rx}$ during Normal Conditions

Eye diagrams of both FSO systems under haze condition are shown in Figure 4. It is seen that in this case also the 4 TX/4 RX , 8 TX/8 RX FSO system performed better. But its $\mathrm{Q}$ factor is less than that of $4 \mathrm{TX} / 4 \mathrm{RX}$ under clear condition. Because attenuation due to haze is higher than that of clear conditions. 




Figure 4.1. Eye Diagram of Single Tx/Rx during Haze

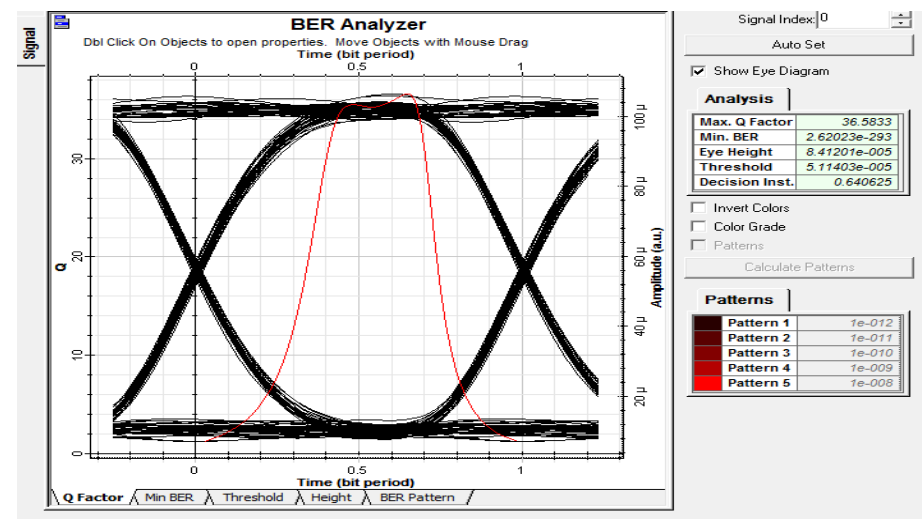

Figure 4.2. Eye Diagram of $4 \mathrm{Tx} / 4 \mathrm{Rx}$ during Haze

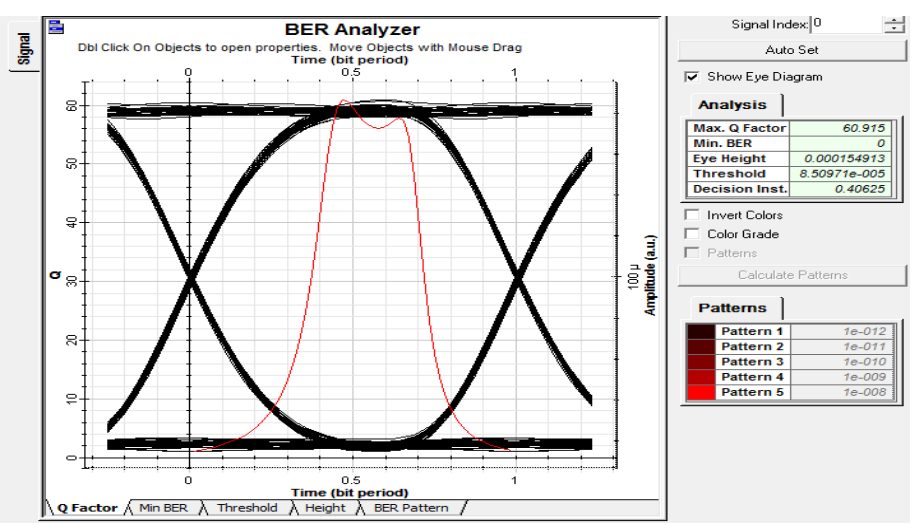

Figure 4.3. Eye Diagram of $8 \mathrm{Tx} / 8 \mathrm{Rx}$ during Haze

The most important challenge faced by FSO system is fog. Its attenuation is taken as $43 \mathrm{~dB} / \mathrm{km}$. In FSO system under fog with same other conditions, it is seen that Q factor of $1 \mathrm{TX} / 1 \mathrm{RX}$ FSO system is only 7.11, $4 \mathrm{TX} / 4 \mathrm{RX}$ is 19.7 while that of $8 \mathrm{TX} / 8 \mathrm{RX}$ is 36 . It is shown in Figure 5. This higher $\mathrm{Q}$ factor obtained is due to spatial diversity. 


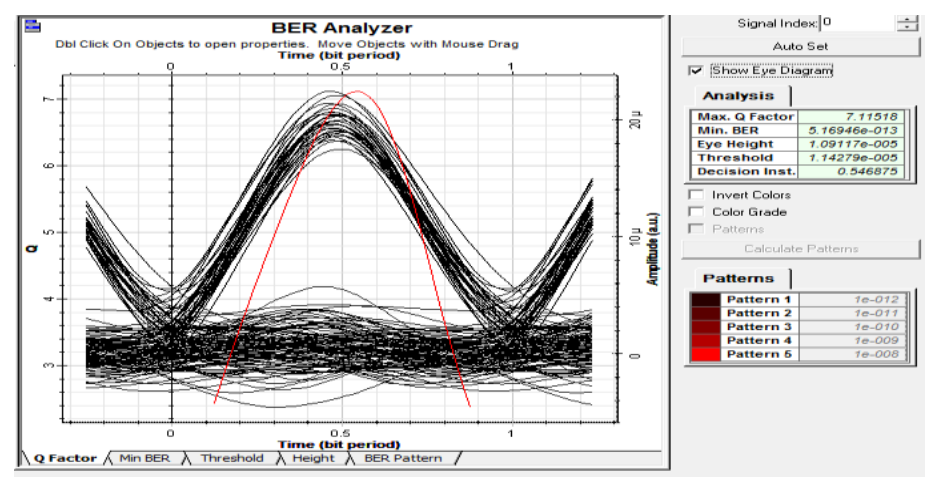

Figure 5.1. Simulation Layout of Single Tx/Rx during Fog

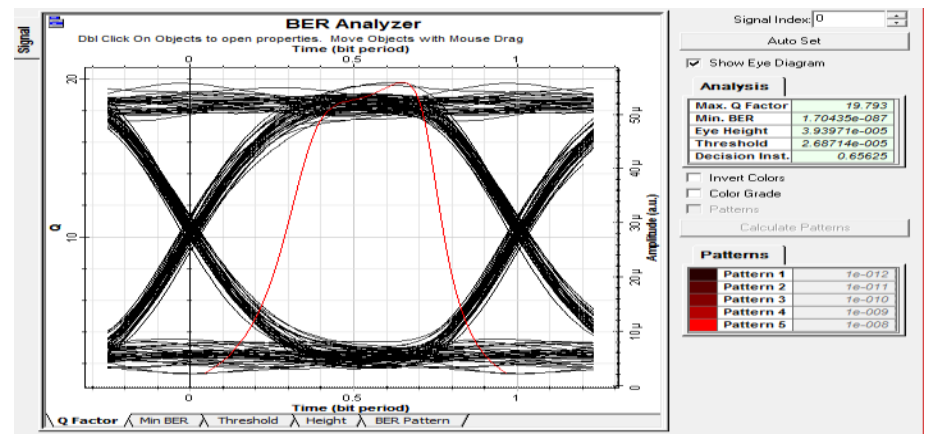

Figure 5.2. Simulation Layout of $4 \mathrm{Tx} / 4 \mathrm{Rx}$ during Fog

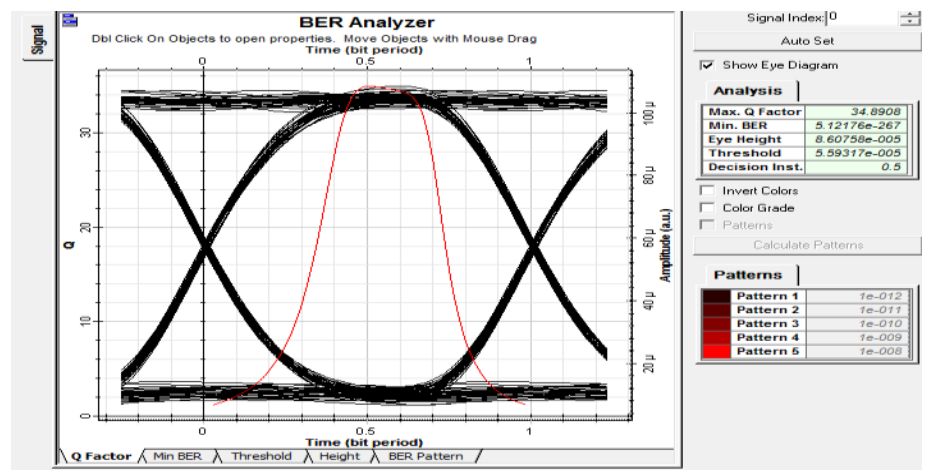

Figure 5.3. Simulation Layout of $8 \mathrm{Tx} / 8 \mathrm{Rx}$ during Fog

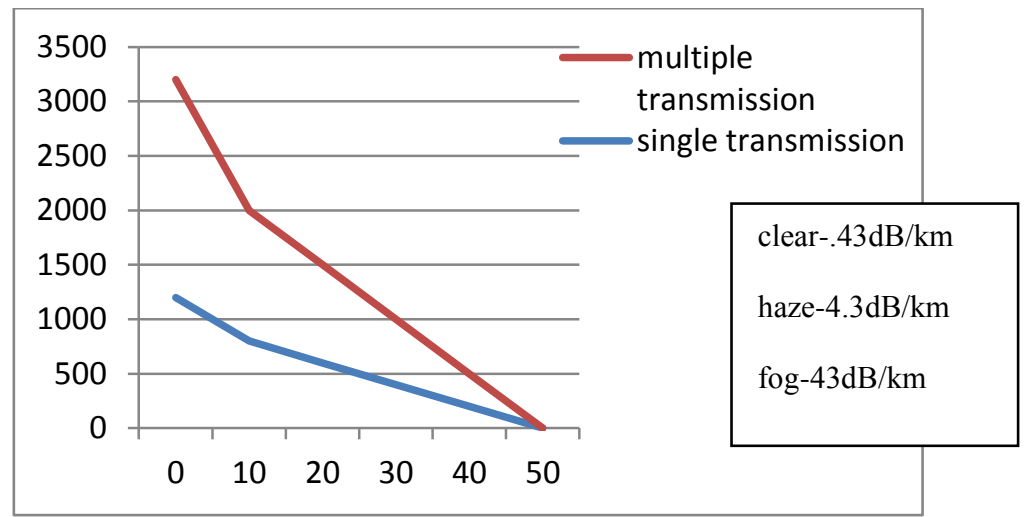

Figure 6. Shows Graphical Comparison between $1 \mathrm{TX} / 1 \mathrm{RX}$ and Multiple TX/RX under the Clear, Haze and Fog Conditions. $Y$ axis Represents the Quality Factor and X Axis Represents the Attenuation in $\mathrm{db} / \mathrm{km}$ 


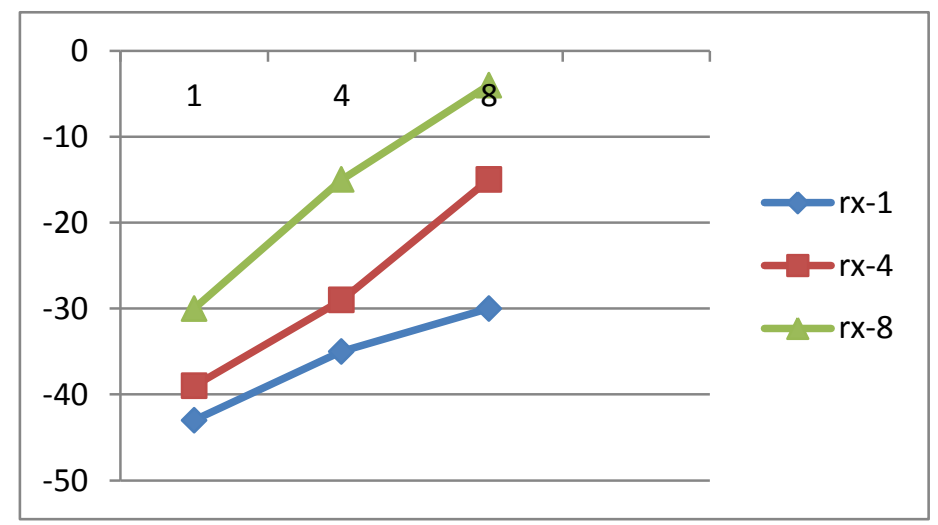

Figure 7. Shows Graphical Comparison between Received Power and Number of Receivers . $Y$ axis Denotes Received Power Level in $\mathrm{dBm}$ and $X$ axis shows Number of Receiver

\section{Conclusion}

In the near future Free Space Optics is a promising communication technology. There is distortion of signals at the receiver due to the atmospheric disturbances. By using new techniques it is possible to reduce the distortion in the atmospheric effects on the optical signal. efficiency is increased by the Incorporation of spatial diversity in the FSO system under different disturbances. Even though $\mathrm{Q}$ factor of FSO system decreases on increasing attenuation, the $8 \mathrm{TX} / 4 \mathrm{RX}$ shows a higher $\mathrm{Q}$ factor and better performances.

\section{Acknowledgments}

The authors would like to thank Guru Nanak Dev University (GNDU) for providing us with optisystem software.

\section{References}

[1] S. Bloom, E. Korevaar, J. Schuster and H. Willebrand, "Understanding the performance of free-space optics", Journal of optical networking, vol. 2, no. 6, (2003) June.

[2] N. Haedzerin, M .D. Noor, A. W. Naji and W. Al Khateeb, "Performance analysis of a free space optics link with multiple transmitters/receivers", IIUM Engineering Journal, vol. 13, no. 1, (2012).

[3] P. W. Raut, Dr. S. L. Badjate, "Diversity Techniques for Wireless Communication", International Journal of Advanced Research in Engineering and Technology, vol. 4, (2013).

[4] S. Asif, Prashant K R. Yadav, "An Overview to Free Space Optics and its advantages over Fiber Optics", International Journal of Electronics and Communication Engineering, vol. 1, (2012) August.

[5] A. Nabih Zaki Rashed Mohamed, and E. M. Amina, "El-Nabawy; The Effects of the Bad Weather on the Transmission and Performance Efficiency of Optical Wireless Communication Systems in: I.J. Image", Graphics and Signal Processing, 10.5815/ijigsp, vol. 7, no. 8, (2012), pp. 68-83.

[6] B. McArthur Kim and E. Korevaar, "Comparison of laser beam propagation at $785 \mathrm{~nm}$ and $1550 \mathrm{~nm}$ in fog and haze for optical wireless communication", Optical Access Incorporated, San Diego, CA, (2001).

[7] V. Sharma and G. Kaur, "Degradation measures in Free Space Optical communication (FSO) and its mitigation techniques - a review", International Journal of Computer Applications, (2012).

[8] R. Kvicala, V. Kvicera, M. Grabner and O. Fiser, "BER and avalibility measured on FSO link", Radioengineering, vol. 16, (2007), pp. 7-12.

[9] X. Zhiu and J. M. Fellow, "Free space optical communication through atmospheric turbulence channels" IEEE transactions on communications, vol. 50, no. 8, (2002) August.

[10] N. A. Mohammad, A. S. El Wakeel and M. H. Aly, "Pointing error in FSO link under different weather conditions", International journal of Video \& Image processing and network security IJVIPNS-IJENS, vol. 12 , no. 01 . 
International Journal of Signal Processing, Image Processing and Pattern Recognition

Vol.8, No.12 (2015)

\section{Authors}

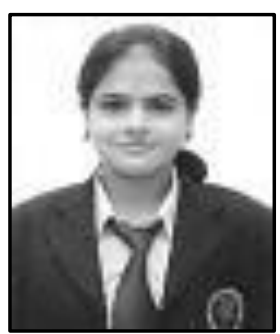

Priyanka sharma, student at Guru Nanak Dev University.

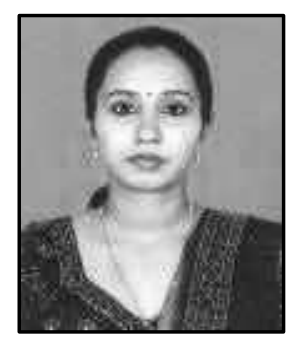

Mrs. Himali sarangal, assistant professor at Guru Nanak Dev University. 